Decreasing the risk of sudden unexpected death in epilepsy: structured communication of risk factors for premature mortality in people with epilepsy

Shankar, Rohit

http://hdl.handle.net/10026.1/11647

10.1111/ene. 13651

European Journal of Neurology

Wiley

All content in PEARL is protected by copyright law. Author manuscripts are made available in accordance with publisher policies. Please cite only the published version using the details provided on the item record or document. In the absence of an open licence (e.g. Creative Commons), permissions for further reuse of content should be sought from the publisher or author. 
DR. ROHIT SHANKAR (Orcid ID : 0000-0002-1183-6933)

DR. BRENDAN MCLEAN (Orcid ID : 0000-0003-1419-8540)

MS. SAMANTHA ASHBY (Orcid ID : 0000-0002-0812-6041)

Article type : Original Article

\title{
Decreasing the risk of SUDEP: Structured communication of risk factors for premature mortality in people with epilepsy
}

\author{
Rohit Shankar ${ }^{1,2} *$, William Henley ${ }^{2}$, Cailin Boland ${ }^{1}$, Richard Laugharne ${ }^{1,2}$, \\ Brendan N. McLean ${ }^{4}$, Craig Newman ${ }^{3}$, Jane Hanna ${ }^{5}$,Samantha Ashby ${ }^{5}$, \\ Matthew C. Walker ${ }^{6}$, Josemir W. Sander ${ }^{6,7,8}$
}

1. Cornwall Partnership NHS Foundation Trust, Threemilestone Industrial Estate Truro TR4 9LD, UK

2. Exeter Medical School, Knowledge Spa, Royal Cornwall Hospital Truro Cornwall TR1 $3 \mathrm{HD}, \mathrm{UK}$

3. Plymouth University Peninsula Schools of Medicine \& Dentistry, John Bull Building, Science Park, 8BU, Research Way, Plymouth PL6 8BT, UK

4. Royal Cornwall Hospital Truro Cornwall TR1 3HD, UK

5. SUDEP Action 12A Mill St, Wantage OX12 9AQ UK

6. NIHR University College London Hospitals Biomedical Research Centre, UCL Institute of Neurology, Queen Square, London WC1N 3BG, UK

7. Chalfont Centre for Epilepsy, Chalfont St Peter, Buckinghamshire SL9 ORJ, UK

8. Stichting Epilepsie Instellingen Nederland (SEIN), Achterweg 5, 2103 SW Heemstede, Netherlands

This article has been accepted for publication and undergone full peer review but has not been through the copyediting, typesetting, pagination and proofreading process, which may lead to differences between this version and the Version of Record. Please cite this article as doi: 10.1111/ene.13651

This article is protected by copyright. All rights reserved. 


\section{*Corresponding author -}

Dr Rohit Shankar

Chy Govenck Threemilestone Industrial Estate Highertown Truro Cornwall UK TR4 9LD.

Telephone-+44-1872221553

Fax: - +44-1872 240765

Email: Rohit.shankar@nhs.net

Running title - Risk monitoring of SUDEP and epilepsy mortality

\section{Conflict of Interest:}

RS, JH \& SA are the main stakeholders of the 'SUDEP and Seizure Safety Checklist'. RS, JH, SA, BNMCL \& CN are developers \& key stakeholders of EpSMon. MCW and JWS are members of the SUDEP and Seizure Safety Checklist review panel. RS has received institutional and research support and personal fees from LivaNova, UCB, Eisai, Special Products, Bial and Desitin outside the submitted work. BNMcL has received research support and personal fees from Eisai, UCB and Desitin outside the submitted work. MCW has received departmental research support from Vitaflo and has been consulted by and received fees for lectures from GSK, Pfizer, Eisai and UCB outside the submitted work. JWS has received departmental research support from Eisai and UCB Pharma and has been consulted by and received fees for lectures from Bial, Eisai, Janssen and UCB Pharma outside the submitted work.

\section{Consent:}

All participants/or their families/carers have provided informed consent for their data to be used used anonymously within the remit of the NHS local Trust policy and governance i.e. of registered audit/service evaluation.

\section{Key Words:-}

Classification; risk assessment, risk stratification, safety check list 


\begin{abstract}
Background

Good practice guidelines highlight the importance of making people with epilepsy aware of the risk of premature mortality in epilepsy particularly due to Sudden Unexpected Death in Epilepsy (SUDEP). The SUDEP and Seizure Safety Checklist ("Checklist") is a structured risk communication tool used in UK clinics. It is not known if sharing structured information on risk factors allows individuals to reduce SUDEP and premature mortality risks.
\end{abstract}

Aim

To ascertain if the introduction of the Checklist in epilepsy clinics lead to individual risk reduction

Method -

The Checklist was administered to 130 consecutive people with epilepsy attending an epilepsy specialised neurology clinic and 129 attending an Intellectual Disability epilepsy clinic within a 4 month period. At baseline, no attendees at the neurology clinic had received formal risk advice while all attending the ID clinic had on multiple occasions for six years. A year later the Checklist was re-administered to each group and scores were compared with baseline and between groups.

Results -

Of 12 risk factors considered there was an overall reduction in mean risk score for the general population ( $p=0.0049$ ) but not for the ID population ( $p=0.322)$. Sub analysis of $25 \%$ at most risk of both populations showed both sets had a significant reduction in risk scores $(p<0.001)$.

\title{
Conclusion -
}

Structured discussion results in behavioural change which reduces individual risk factors. This impact seems higher in those who are at higher risk currently. It is important clinicians share risk information with individuals as a matter of public health and health promotion.

This article is protected by copyright. All rights reserved. 


\section{Introduction}

People will generally modify behaviour and change lifestyle if they feel that there is an advantage or benefit. People need to have a comprehensive understanding of specific risks. Health risks are conveyed by clinicians in a myriad of ways of variable quality and effectiveness. A host of clinical and individual factors play a role in person-centred communication [1]. The lack of a clear structure to capture this quality of communication could influence outcomes.

New guidance from The American Academy of Neurology (AAN) recognises the importance of communicating the risk of Sudden Unexpected Death in Epilepsy (SUDEP) to people with epilepsy [2] mirroring the UK's National Institute of Clinical Excellence (NICE) [3] epilepsy guidance. Both guidelines lack elaboration on how to deliver person centred risk assessment. Another concern is epilepsy risk discussion is expected to occur shortly after diagnosis. It has, however, been shown in chronic conditions such as epilepsy, that risk can change over time and is influenced by varying life factors [4]. People with epilepsy are rarely aware of changing risk often to their detriment. Thus what can start as 'low' risk can over time switch to a 'higher' risk without the individual, carers or the clinician being fully aware [5]. It is therefore important to update risk assessment and feedback based on the course of an individual's epilepsy and how it may change.

There are about half a million people with epilepsy in the UK and in 2013, almost 1200 of them died as a result of epilepsy, roughly the same number who died from asthma in the same year [6]. This is despite the number of people with asthma being 10 times greater [6]. Over a third of epilepsy deaths could have been avoidable whilst only a quarter of asthma deaths were identified as preventable [6]. This suggests that there is significant room for improvement in the way risk identification and management of people with epilepsy can be delivered. It has been shown that the risk of premature mortality risk in epilepsy is rarely practiced due to lack of clarity of what needs to be said [7]. A recent survey suggests that many specialists do not discuss SUDEP and that risk discussion is arbitrary led by clinician judgment [8].

A safety checklist was developed which uses available evidence to determine 19 SUDEP risk factors divided into modifiable and non-modifiable risks [9]. These are on seizures, physical health, psychological and social issues, thus providing individuals a holistic overview of their current situation [9]. These factors were subsequently examined in those who had died from SUDEP $(n=48)$ in the UK county of Cornwall (population 550,000) between $2004-2012$ compared with people with epilepsy still living [4]. It was found that 17 factors were associated with SUDEP and directly relevant for people living with epilepsy [10] ${ }^{1}$. These 17 factors form the background of the Seizure and SUDEP safety checklist ("Checklist") (https://www.sudep.org/checklist), a 10 minute risk communication tool and the selfmonitoring of epilepsy risk mobile app EpSMon [11]. The Checklist considers risk factors associated with epilepsy mortality, including but not restricted to SUDEP. The Checklist is

This article is protected by copyright. All rights reserved. 
provided in appendix 1(supplementary data) and key risk factors and their narrative are listed in table 1 (modifiable factors indicated as ' $M$ ').

Of the 19 factors in the original Checklist, twelve were considered modifiable $[4,5,10]$ and seven non-modifiable, focussing clinicians' discussions with individuals on modifiable factors. It can be repeated annually, when risk factors change at follow up or when there is a treatment change.

\section{Aim}

We aimed to determine whether the introduction of a risk communication checklist in an epilepsy clinic leads to a reduction in individual SUDEP and epilepsy mortality risk factors.

\section{Method}

We used the Checklist prospectively in two sets of specialist secondary care epilepsy clinics in Cornwall as part routine clinical practice and audited the findings after two applications one year apart. The first was a neurology epilepsy clinic. None of those referred to the neurology clinic had previous counselling concerning SUDEP risk. The population in this clinic included people with newly diagnosed epilepsy; people with epilepsy re-referred from primary care and those with treatment resistant epilepsy on routine follow up.

The second clinic specialized in epilepsy and intellectual disability (ID) in which discussion of SUDEP risk had been the practice since 2010. All attendees have moderate to profound ID and thus are in twenty four hour supported care with a designated carer or a family member. The administration of the checklist in this group was directly to a family member or carer. Where eligible i.e. individual was capable to process risk, feedback was also given by an 'easy read' format to the individual. Due to previous exposure to discussion of SUDEP risk and being in 24/7 supported care environment and having a nominated carer to deliver actions this population was considered an appropriate comparison group. One would expect that the majority of the modifiable risk factors in this population are better controlled due to the level of supervision and monitoring people with ID receive in comparison to the general population. All those attending this clinic were recognised to have treatment resistant epilepsy on routine 3 monthly follow ups.

Those with epilepsy attending these clinics between November 2015 and March 2016 were counselled on their personal SUDEP and epilepsy risk using the Checklist. The checklist was administered by an epilepsy nurse or by a specialist who had training in doing so. No baseline comparison between these two populations was done at the start of the project.

This article is protected by copyright. All rights reserved. 
One year later all underwent the application of the checklist to ascertain if the advice provided using the checklist had reduced risk scores. Numbers of those discharged from both clinics in the interim one year were excluded. The focus was on the 12 modifiable risks.

Seizure change was recorded from case notes by using changes in seizure frequency by counting seizures reported and recorded at clinic appointments in the interim between the applications. 'Change' was defined as at least $25 \%$ change in frequency constant for at least 6 months till the re-application of the checklist.

The demographic characteristics and risk factors were summarized at baseline in both populations using percentage frequencies for categorical variables, and means and standard deviations for the continuous variables. These summary measures were compared across groups to identify baseline differences between the two groups. McNemar's test was used to test where there were changes in individual risk factors from baseline to follow-up in each clinic group. The threshold for declaring statistical significance was set at $p<0.05$.

A risk index was created whereby individuals receive a score of 1 for each modifiable risk factor and 0 if they do not have the risk factor. The total score is obtained by a simple sum of the values from 12 risk factors. The distribution of risk scores was plotted separately at baseline and follow-up for each group using boxplots. Differences in the risk scores between baseline and follow-up were assessed using paired t-tests.

To determine if the Checklist had also made a difference in those identified as the most at risk, the baseline risk scores were ranked separately in each group and a threshold score chosen such that approximately top $25 \%$ scored above the threshold were sub analysed and compared. This was done by selecting individuals with a baseline risk score of 5 or more in each group. Changes in risk scores between baseline and follow-up were compared within these high risk sub-groups as above.

As this exercise did not involve treatment changes, interventions or randomization and as the Checklist is routinely used it was registered as a service evaluation.

\section{Results}

The checklist was applied to 130 consecutive individuals in the neurology clinic and similarly to 129 people in the ID clinic. Demographic and clinical details are provided in table 2. During the following year 39 and 36 of the original cohorts were lost to follow up or discharged from their respective services thus not available for the second check. Therefore, 91 individuals were available from the neurology clinic and 93 ID cohorts for the second application. The epilepsy duration at baseline had a broad distribution in the general population with $41 \%$ having seizures for less than 5 years and $32 \%$ having seizures over 15 years whereas over $90 \%$ of the ID population had seizures over 15 years. Twenty eight 
percent of the general population had generalised seizures as compared to $68 \%$ with ID. Group differences at baseline were significant for age $(p=0.01)$, number of AEDs $(p<0.001)$, seizure duration $(p<0.001)$ and type i.e. generalised epilepsy $(y / n ; p<0.001)$ and for alcohol abuse $(p=0.002)$. All other group variables (Table 1$)$ were non-significant $(p \geq 0.05)$.

Changes to the 12 risk factors individually considered are shown in Tables 3 \& 4 . Figure 1 shows the distribution of risk scores at baseline and follow-up separately for the general and the ID populations. There was an overall reduction in mean risk score for the general population ( $p=0.049$ paired $t$-test) but not for the ID population $(p=0.322)$. Groups differences in terms of overall reduction in mean risk score was not significant $(p=0.38)$. Risk scores were ranked by selecting the top $25 \%$ of each group (table 5 ). In both cases, there was a statistically significant mean reduction in risk score $(p<0.001)$. End analysis of the sub groups of those with a risk score of 5 and above at baseline, showed there was a significant difference between groups with the general population experiencing a greater reduction in risk scores $(p=0.03)$.

\section{Discussion}

Using the Checklist stimulated open discussions about SUDEP risk. The exercise has acted as a catalyst to improve care and outcomes in the longer term. The value of education and empowerment is intuitive in all areas of clinical risk reduction and is particularly relevant in epilepsy.

This is a before and after assessment of the introduction of the Checklist in the general neurology clinic. There may be confounders contributing to the change in risk status, as, for instance, changes in treatment could have reduced risk independently. Ideally, the Checklist should have been being validated using a randomized control approach in which controls receive no information on SUDEP which is currently the practice in many sites. This could, however, be deemed non-ethical as withholding safety information could have implications. Using the ID clinic as a comparison group, however, provides some strengths to the findings as the Checklist had long been used in this setting and modifiable factors were considered addressed in this population. Unlike other parts of the UK, Cornwall decommissioned long stay institutions and hospitals for people with ID over ten years ago. Most people with ID now live in bespoke placements in the community and are supported on an as required basis for their specific needs. The Checklist is used regularly in this population to communicate and mitigate risks. Thus this population had been previously exposed to the 'intervention' while the general population had not.

This is not an ideal comparator especially as this group has more treatment resistance and multimorbidity. The two groups could be seen as separate but affiliated cohorts with some shared commonality such as seizures. Issues such as harmful use of alcohol, 24/7 supervision, assured compliance, reliable seizure feedback from care providers may be confounders.

This article is protected by copyright. All rights reserved. 
The focus is on examining if the Checklist could lead to change in modifiable risk factors by structured communication. Thus irrespective of the nature of the groups, the study ascertains if the Checklist positively influenced a change in modifiable risk especially in the general population group when compared to the ID group. The focus is on changes within each group over a year period.

Looking at the change from baseline with regard to specific factors the general population group showed significant reduction in the factors of seizure frequency $(p=0.019)$ and severity $(p<0.001)$. This suggests that safety advice has possible direct implications on seizure factors. As seizure frequency is the single most important factor associated with SUDEP change would make people safer. The other factor which showed significant change was sleeping posture $(p=0.046)$. While advice was given of this risk and people appear to have made an effort to change their sleeping posture consciously little can be yet said of its utility.

In the ID population no change in modifiable factors had been expected. This was largely true other than for a positive and significant association to the treatment of depression $(p=0.046)$. This did not correspond to a direct change in seizure factors or overall risk.

Even in the ID population which at baseline was thought to be 'non-modifiable' from a risk perspective had a noticeable improvement in the top $25 \%$ scores. This highlights that modifiable factors such as seizure frequency often fluctuate over time requiring ongoing vigilance.

There were differences between groups in terms of seizures and number of AEDs which may also introduce bias. About a third of both cohorts were lost for the second assessment and it is unclear if the Checklist had an impact on them.

This is one of the first attempts to measure the impact of the introduction of a safety Checklist in SUDEP and seizure risk management. It would be important to evaluate the effectiveness of health promotion measures such as this list in other clinical settings. Our project also challenges views that attitudes to SUDEP cannot be altered by counselling. A small study in young adults had shown a cynical view from the young people [12] and it could be argued that a lack of structured engagement especially identifying clear areas of change might have been a possible reason for such an attitude.

Implications for clinical practice

This supports the introduction of a safety Checklist as it provides some evidence that people with epilepsy and their carers respond to the Checklist in a way as to seizure risk. Creating such baseline scores and risk stratification for known risk factors is a first step in improving awareness among individuals with epilepsy and also clinicians in such settings. Having

This article is protected by copyright. All rights reserved. 
ongoing risk discussions, using tools such as the Checklist, to reduce these risks where possible must follow to help tackle premature mortality. Further as this enables a clinician patient partnership it helps overcome possible hurdles for clinicians and reduces ambiguity which could have resulted in the lack of risk communication of risk to-date $[7,8]$.

Implications for policy

Promoting health promotional checklists in epilepsy may reduce morbidity and mortality as risk factors can be modifiable and change over time and this has important public health implications.

\section{References: -}

1. https://www.fda.gov/downloads/AboutFDA/ReportsManualForms/Reports/UCM268069.pdf accessed on $11 / 05 / 2017$

2. Harden C, Tomson T, Gloss D et al Practice guideline summary: Sudden unexpected death in epilepsy incidence rates and risk factors: Report of the Guideline Development, Dissemination, and Implementation Subcommittee of the American Academy of Neurology and the American Epilepsy Society April 25, 2017, 88:17 1674-1680

3. Clinical Guideline 137 NICE Partial pharmacological update of clinical guideline 20: the epilepsies: the diagnosis and management of the epilepsies in adults and children in primary and secondary care. London: National Clinical Guideline Centre; 2012 January: 22.

4. Shankar R, Jalihal V, Walker M et al. A community study in Cornwall UK of sudden unexpected death in epilepsy (SUDEP) in a 9-year population sample Seizure. 2014; 23(5), 382-385.

5. Shankar R, Donner E, McLean B et al Sudden Unexpected Death in Epilepsy -What Every Neurologist Should Know Epileptic Disorders Volume 19, Issue 1 March 2017 Pages 1-9

6. Office for National Statistics. Death registrations summary table, England and Wales 2013.

7. Waddell, B. McColl K, Turner $\mathrm{C}$ et al. Are we discussing SUDEP?-A retrospective case note analysis Seizure. 2013; 22(1), $74-76$.

8. Strzelczyk A, Zschebek G, Bauer S et al. Predictors of and attitudes toward counselling about SUDEP and other epilepsy risk factors among Austrian, German, and Swiss neurologists and neuropediatricians. Epilepsia. 2016;57(4):612-20.

9. Shankar R, Cox D, Jalihal V et al Sudden unexpected death in epilepsy (SUDEP): Development of a safety checklist. Seizure 2013, 22 (10) , pp. 812-817

10. Shankar R, Walker M, McLean B et al A step to modify and prevent SUDEP- The validity of risk factors in the SUDEP and Seizure Safety Checklist: a case control study Journal of Neurology DOI $10.1007 / \mathrm{s} 00415-016-8203-3$

This article is protected by copyright. All rights reserved. 
11. Shankar R, Newman C, Mclean B et al. Can technology help reduce risk of harm in patients with epilepsy? B J Gen Practice 2015;65:448-9

12. Harden, J., Tonberg, A., Chin, R.F et al 'If you're gonna die, you're gonna die': Young adults' perceptions of sudden unexpected death in epilepsy. Chronic IIIn. 2015 Sep;11(3):230-41.

Table 1: Key Risk Factors of SUDEP and Seizure Safety and their description: Adapted from https://sudep.org/checklist ${ }^{11,12,13}$

Modifiable factors are identified as (M) next to them.

\section{Severity of seizures (M)}

This is evidenced by an increase in the last 6 months of the administration of rescue medication such as Midazolam, paramedic call outs or ED visits as recorded in clinical notes

\section{Compliance issues (M)}

This factor is defined by finding of variable AED hair strand levels in SUDEP group. Compliance issues were also assessed via patient reporting as evidenced by medical records in both groups. Adherence issues (including not picking up prescriptions) found as a factor across all epilepsy-related deaths as increasing risk by $50 \%$

\section{Frequent AED changes (M)}

This is defined as where the changes of dose or medication were not following British National Formulary (BNF) guidance on titration in the last 6 months.

\section{Sub therapeutic AED levels}

Is a finding linked closely to compliance

\section{Alcohol problem (M)}

Is defined as where there is a clinically definable alcohol disorder as identified by the WHO ICD 10 diagnostic Manuel. A systematic analysis of epilepsy deaths confirmed this risk factor.

\section{Depression treatment (M)}

This is defined as having clinical depression as per ICD 10 /DSMV and/or being on antidepressant medication' as defined by BNF 4.3 and/or having therapy/counseling for depression.

Currently it is unclear how relevant a risk or a safety factor depression or its treatment particularly SSRIs are. This is has not been clearly defined.

This article is protected by copyright. All rights reserved. 


\section{Presence of anxiolytic medication (M)}

This is defined as having 'anxiolytic medication' as defined by BNF 4.1.2

Currently it is unclear how relevant a risk factor this is as it has not been clearly defined.

\section{Night surveillance (M)}

Nocturnal Seizures were shown to have a 4 fold increased risk and accounted for $60 \%$ of all SUDEPs in large control study. Nocturnal surveillance thus where present is considered to be a protective factor.

\section{Sleeping in prone position (M)}

Independent risk factor evidenced by several studies including a systematic review.

The prone position is defined as lying on the belly, chest, or face, with or without obstruction of the nose or mouth. Sleeping in the prone position or remaining in a prone position post seizure is considered a risk.

\section{Convulsive Seizures (M)}

Combined data from the previous four case-control studies found this is the most important risk factor

Increasing seizure frequency (M)

Active Seizures which in the last 6 months were noted to worsen in frequency of $>25 \%$

Assessment for epilepsy surgery (M)

Where available or referred to tertiary centres if eligible can have a positive impact on seizures and SUDEP

\section{Duration (>15 years)}

This has been suggested by several studies, but not after multiple logistical regression analysis for seizure frequency

\section{Early onset epilepsy}

Where the onset of epilepsy is before the age of 15 years

This article is protected by copyright. All rights reserved. 
Table 2: Description of the participants and their risk factors of the Specialist General Population epilepsy clinic and the specialist Intellectual Disability (ID) epilepsy clinic at baseline (number and percentage except where shown otherwise)

\begin{tabular}{|c|c|c|c|}
\hline 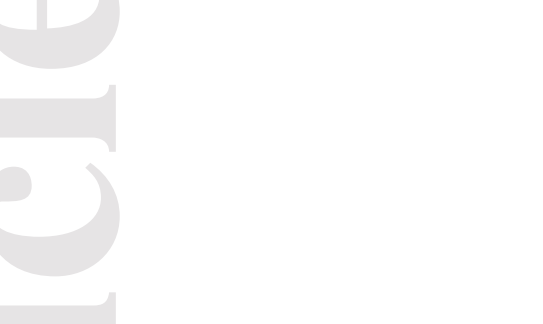 & General $(n=130)$ & ID (n=129) & $\begin{array}{l}\text { P value provided where } \\
\text { significant. All other } \\
\text { group differences at } \\
\text { baseline for variables } \\
\text { were non-significant } \\
\text { (p } \geq 0.05) \text {. }\end{array}$ \\
\hline \multicolumn{4}{|l|}{ Gender } \\
\hline Male & $72(55 \%)$ & 75 (58\%) & \\
\hline Female & $58(45 \%)$ & $54(42 \%)$ & \\
\hline $\begin{array}{l}\text { Age (years): Mean as Standard } \\
\text { Deviation (SD) }\end{array}$ & $42(20)$ & 37 (14) & $p=0.01$ \\
\hline Duration of epilepsy & & & $p<0.001$ \\
\hline$<5$ years & 53 (41\%) & $7(5 \%)$ & \\
\hline $5-10$ years & $29(22 \%)$ & $1(1 \%)$ & \\
\hline $10-15$ years & $6(5 \%)$ & $3(2 \%)$ & \\
\hline $15+$ years & $42(32 \%)$ & 117 (91\%) & \\
\hline Unknown & 0 & 1 & \\
\hline \multicolumn{4}{|l|}{ P } \\
\hline Generalised Epilepsy & & & $p<0.001$ \\
\hline Yes & $36(28 \%)$ & $87(68 \%)$ & \\
\hline No & 93 (72\%) & $41(32 \%)$ & \\
\hline Unknown & 1 & 1 & \\
\hline \multicolumn{4}{|l|}{$\begin{array}{l}\text { Presence of intellectual } \\
\text { disability }\end{array}$} \\
\hline Yes & $0(0 \%)$ & $129(100 \%)$ & \\
\hline No & $130(100 \%)$ & $0(0 \%)$ & \\
\hline
\end{tabular}

This article is protected by copyright. All rights reserved. 


\begin{tabular}{|c|c|c|c|}
\hline $\begin{array}{l}\text { Severity of seizures in last 3-6 } \\
\text { months }\end{array}$ & & & \\
\hline Increasing & $43(33 \%)$ & $36(28 \%)$ & \\
\hline Stable & $61(47 \%)$ & $64(50 \%)$ & \\
\hline Decreasing & 25 (19\%) & $29(22 \%)$ & \\
\hline Unknown & 1 & 0 & \\
\hline \multicolumn{4}{|l|}{ res } \\
\hline $\begin{array}{l}\text { Number of Antiepileptic drugs } \\
\text { (AEDs) } \\
\text { baseline: Mean (SD) }\end{array}$ & $1.4(0.6)$ & $2.2(1.0)$ & $P<0.001$ \\
\hline $\begin{array}{l}\text { Number of AEDs endpoint } \\
\text { :Mean (SD) }\end{array}$ & $1.5(0.6)$ & $2.1(1.0)$ & $P<0.001$ \\
\hline \multicolumn{4}{|l|}{7} \\
\hline \multicolumn{4}{|l|}{ Compliance issues } \\
\hline Yes & $15(12 \%)$ & $14(11 \%)$ & \\
\hline No & 115 (88\%) & 115 (89\%) & \\
\hline Unknown & 0 & 0 & \\
\hline$\square$ & & & \\
\hline Reported alcohol problems & & & $P=0.002$ \\
\hline Yes & $12(9 \%)$ & $1(1 \%)$ & \\
\hline No & 117 (91\%) & 128 (99\%) & \\
\hline Unknown & 1 & 0 & \\
\hline
\end{tabular}

This article is protected by copyright. All rights reserved. 
Table 3: Univariate analysis of change in behaviour for general population one year post baseline

\begin{tabular}{|c|c|c|c|c|c|}
\hline Risk factor & $\begin{array}{l}\text { positive } \\
\text { change }\end{array}$ & no change & $\begin{array}{l}\text { negative } \\
\text { change }\end{array}$ & No data & $p$-value* \\
\hline \multicolumn{6}{|l|}{ Modifiable factors } \\
\hline Severity of seizures & 22 & 53 & 15 & 40 & $<0.001$ \\
\hline Number of AEDs & 4 & 79 & 8 & 39 & 0.387 \\
\hline Compliance issues & 8 & 77 & 6 & 39 & 0.789 \\
\hline Frequent AED prescribing issues & 4 & 86 & 1 & 39 & 0.371 \\
\hline Sub therapeutic AED levels & 5 & 86 & 0 & 39 & 0.074 \\
\hline Reported alcohol problem & 9 & 78 & 3 & 40 & 0.149 \\
\hline Treatment for depression & 2 & 85 & 3 & 40 & 1.000 \\
\hline Anxiolytic medication & 1 & 87 & 3 & 39 & 0.617 \\
\hline \multicolumn{6}{|l|}{ Moderate risk-modifiable factors } \\
\hline No surveillance at night & 9 & 73 & 9 & 40 & 1.000 \\
\hline Prone position & 8 & 77 & 1 & 44 & 0.046 \\
\hline Failed assessment for epilepsy surgery & 0 & 90 & 1 & 39 & 1.000 \\
\hline 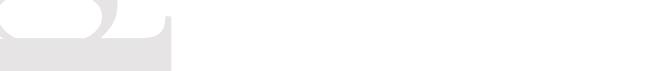 & & & & & \\
\hline \multicolumn{6}{|l|}{ Established risk-modifiable factor } \\
\hline $\begin{array}{l}\text { High seizure frequency especially } \\
\text { convulsive seizures }\end{array}$ & 17 & 69 & 5 & 39 & 0.019 \\
\hline & & & & & \\
\hline
\end{tabular}

*McNemar's test

This article is protected by copyright. All rights reserved. 
Table 4: Univariate analysis of change in behaviour for ID population one year post baseline

\begin{tabular}{|c|c|c|c|c|c|}
\hline Risk factor & $\begin{array}{l}\text { Positive } \\
\text { change }\end{array}$ & No change & $\begin{array}{l}\text { Negative } \\
\text { change }\end{array}$ & No data & p-value* \\
\hline \multicolumn{6}{|l|}{ Modifiable factors } \\
\hline Severity of seizures & 28 & 35 & 30 & 36 & 0.960 \\
\hline Number of AEDs & 18 & 64 & 11 & 36 & 0.683 \\
\hline Compliance issues & 7 & 83 & 2 & 37 & 0.182 \\
\hline Frequent AED prescribing issues & 6 & 84 & 3 & 36 & 0.505 \\
\hline Sub therapeutic AED levels & 0 & 90 & 0 & 39 & 1.000 \\
\hline Reported alcohol problem & 1 & 92 & 0 & 36 & 1.000 \\
\hline Treatment for depression & 1 & 83 & 8 & 37 & 0.046 \\
\hline Anxiolytic medication & 3 & 89 & 1 & 36 & 0.617 \\
\hline \multicolumn{6}{|l|}{ Moderate risk-modifiable factors } \\
\hline No surveillance at night & 8 & 73 & 9 & 39 & 1.000 \\
\hline Prone position & 5 & 46 & 2 & 76 & 0.450 \\
\hline $\begin{array}{l}\text { Failed assessment for epilepsy } \\
\text { surgery }\end{array}$ & 3 & 83 & 1 & 42 & 0.617 \\
\hline \multicolumn{6}{|l|}{ Established risk-modifiable factor } \\
\hline $\begin{array}{l}\text { High seizure frequency especially } \\
\text { convulsive seizures }\end{array}$ & 7 & 76 & 10 & 36 & 0.628 \\
\hline & & & & & \\
\hline
\end{tabular}


Table 5: Comparison of the risk score changes in modifiable factors over one year of the $25 \%$ most risky of the two cohorts

\begin{tabular}{|l|l|l|l|}
\hline \multicolumn{4}{|c|}{ Change in risk in both groups of people having 5 or more risk factors (top 25\%) } \\
\hline & $\begin{array}{l}\text { Baseline number of } \\
\text { people with over 5 risk } \\
\text { factors }\end{array}$ & $\begin{array}{l}\text { After one year } \\
\text { number of people with } \\
\text { over 5 risk factors }\end{array}$ & Change \\
\hline General $(n=91)$ & 19 & 2 & $p<0.001$ \\
\hline ID (n=93) & 20 & 6 & $p<0.001$ \\
\hline
\end{tabular}

This article is protected by copyright. All rights reserved. 
Figure 1 Distribution of risk scores at baseline and follow-up in the general and ID clinic populations
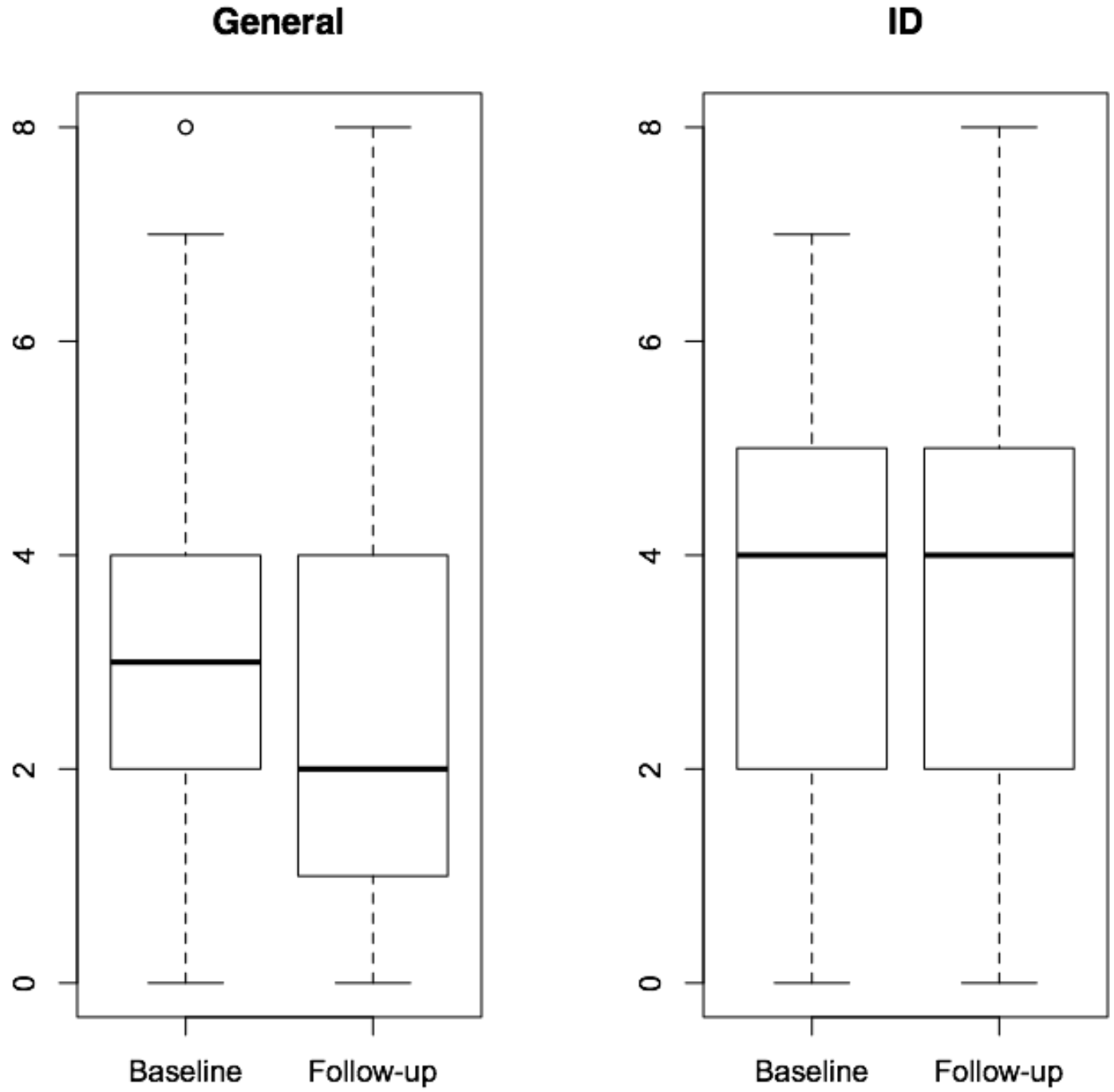

This article is protected by copyright. All rights reserved. 


\section{Acknowledgements}

MCW and JWS are based at UCLH/UCL Comprehensive Bio-Medical Research Centre, which received a proportion of funding from the Department of Health's NIHR Biomedical Research Centres funding scheme. JWS current position is endowed by the UK Epilepsy Society and he receives research support from the Dr. Marvin Weil Epilepsy Research Fund. WH was funded by the National Institute for Health Research (NIHR) Collaboration for Leadership in Applied Health Research and Care (CLAHRC) for the South West Peninsula. The views expressed in this publication are those of the authors and not necessarily those of the NHS, the NIHR or the Department of Health.

This article is protected by copyright. All rights reserved. 